\title{
Mathematical optimization and engineering applications
}

\author{
Kulcsár T., Timár I. \\ Department of Mechanical Engineering, University of Pannonia \\ 10 Egyetem str., 8200 Veszprem, Hungary
}

\begin{abstract}
New challenges raised almost in all segments of the global economy in the last two decades. The energy-, finance-, environmental crises, as well as the intensive use of natural resources require new design methods in the engineering activity, for both the product design and the manufacturing process planning. An effecting tool to be competitive is to apply the optimum design methods to the engineering tasks. This paper reviews the different methods of mathematical optimization, which are widely used for solving engineering problems, and describes the application of this method for two different cases. The first sample shows how to find the optimal dimensions of the welded, box type frame of a freight bogie, which will minimize the manufacturing cost of the structure and will satisfy several restrictions, e.g. mechanical stress limit, dimensional constraints, buckling, and fatigue conditions. The other case is to find the optimal geometric dimensions of a pipe insulation system which will result in a minimum investment and operating cost, when the heat loss and the outside surface temperature are restricted.
\end{abstract}

Keywords: mathematical optimization, optimal design of railway bogie, optimization of insulated pipeline.

2000 MSC: $90 \mathrm{C} 90,74 \mathrm{P} 10$

UDC: 519.85

\section{Introduction}

The continuous increasing trends in the case of the raw material-, energy-, production-, and operation costs have been made necessary, the development of the numerical methods made it possible to spread widely the optimal design methods in the technical practice. Using these methods we can meet not only the different requirements, but also we are able to reduce the cost level of the product. The reduction of the structural mass or volume was the target at the early stage of the optimal design studies. Later the overall cost of the product was the goal to be reduced.

We have to know the mathematical methods as well as the technical and engineering background of the task for the efficient application of the optimal design methods. A brief overview is given on the mathematical bases and also some technical applications are presented in this paper.

\section{General formulation of the optimum design}

Any kind of optimization problem can be formulated to find the appropriate set of the design variables in the multidimensional parameter-space, which can optimize the objective function. In general, the minimum (or maximum) of the objective function $f(\boldsymbol{x})$ in an $n$-dimensional, Euclidean space $\mathbb{R}^{n}$ is to be searched. The result of the optimization can be illustrated thus by one point or a vector in this solution space. In the mathematical notation, the optimization problem can be generally represented, as

$$
\begin{gathered}
\min f(\boldsymbol{x}), \quad \boldsymbol{x} \in \mathbb{R}^{n}, \\
0 \leqslant g_{j}(\boldsymbol{x}), \quad j=1,2, \ldots, m, \\
0=h_{j}(\boldsymbol{x}), \quad j=m+1, \ldots, p,
\end{gathered}
$$


where $\boldsymbol{x}=\left[x_{1}, x_{2}, \ldots, x_{n}\right]^{\mathrm{T}}$ is the vector of the unknown quantities, $g_{j}(\boldsymbol{x})$ and $h_{j}(\boldsymbol{x})$ are, respectively, the inequality and the equality constraints, $m$ and $p$ are integer numbers. Any point $\boldsymbol{x}$ - that satisfies these equations - is called a feasible point or feasible solution of the optimum design problem. The design parameters (variables) can be dimensions, technology parameters, physical attribute (temperature, pressure) strength parameters. The variables may have discrete or continuous distribution.

The objective function may contain the raw material cost, the manufacturing costs, the assembly costs, the operation costs, the maintenance costs and also the costs related to the recycling at the end of the lifetime, some special cases it is the stiffness of the construction (buckling), or the eigenvalue of structure [1]. Also constraints have to be established reflecting the special requirements to be fulfilled. The constraints can be formulated, as inequality constraints $\left(0 \leqslant g_{j}(\boldsymbol{x})\right)$, or equality constraints $\left(0=h_{j}(\boldsymbol{x})\right)$. The physical content of the constraint functions can be the limitation of the mechanical stresses, deformations, buckling criteria, surface temperature, etc.

The functions (objective function and constraints) may be linear, nonlinear, or special functions. Due to that fact, solving this equation system will cause difficulties. The mathematical methods developed to solve the optimum tasks relating to the handle of optimal problem described in (1). The suitable solving method for the optimizing problem can be selected depending on the actual form of the objective function and the constraints.

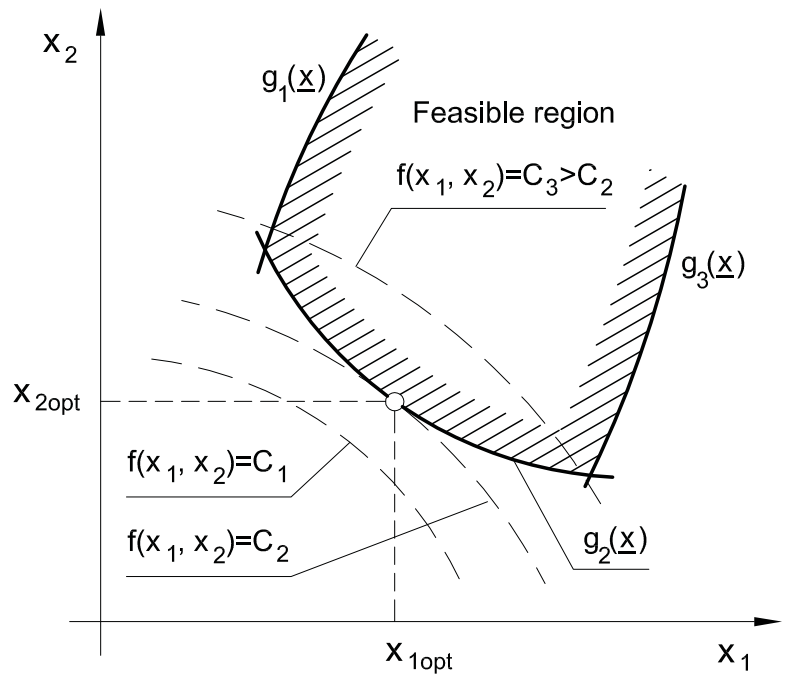

Fig. 1. Optimum task with 2 variables.

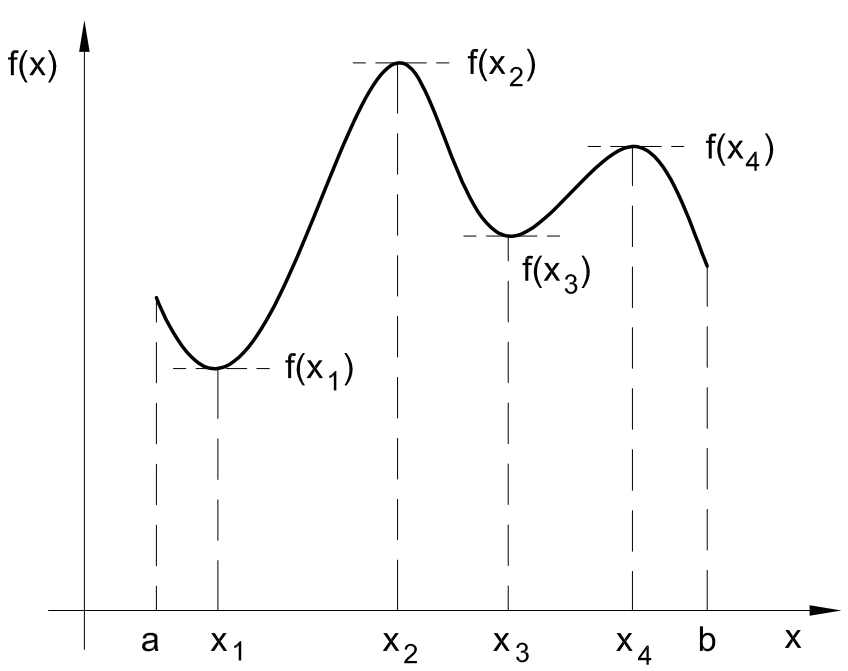

Fig. 2. Relative and global maxima and minima.

The optimum design problem with 2 design variables and 3 constraints can be easily described graphically (Fig. 1). The 3 inequality constraints $g_{1}(\boldsymbol{x}), g_{2}(\boldsymbol{x}), g_{3}(\boldsymbol{x})$ will figure the area of the feasible variables in the $x_{1}-x_{2}$ coordinate system. Have to find the point(s) of the feasible area, which will minimize the objective function. Describing the objective function with 3 different $C_{1}, C_{2}$, and $C_{3}$ values, the positions of the function graph is parallel. The optimum solution of the problem $\left(x_{1 \text { min }}, x_{2 \text { min }}\right)$ will be determined by the tangent point of the objective function curve set and the boundary curve of the feasible area $\left(g_{2}(\boldsymbol{x})\right)[2]$.

In the case of more complex functions there could be not only one, but more local minimum points (Fig. 2). Solving real technical problems the main target is to find the one from the local minimum values, which provides the smallest value, so called global minimum value of the optimal problem. The figure shows, that $x_{1}$ and $x_{3}$ provide local minimum values, but $x_{1}$ gives us the global minimum point. Similarly, $x_{2}$ and $x_{4}$ provide local maximum values. The global maximum value will appear at $x_{2}$. When the feasible area of the independent variables is convex, the local minimum is identical to the global one [3]. 


\section{Local and global maximum and minimum}

The majority of the optimizing procedures usually supply local optimum solution, but it is possible, that these local optimum points are also global ones. In the case of a local optimum is reached, the solution point will be a better starting point (starting vector) for further calculation in order to reach the global optimum solution. In the case when we are interesting to find the global optimum solution, than it is a possible strategy to use different starting vectors, and to perform the optimization process several times. However we have to remark, that a global optimum solution will exist only in a convex space of the design variables.

\section{Necessary and sufficient condition of the extrema of a multivariable function}

We will formulate the necessary and sufficient condition for the existence of the extrema at a multivariable function with the help of the Hessian matrix containing second order partial derivates [4]. Let the function

$$
f\left(x_{1}, x_{2}, \ldots, x_{n}\right)
$$

with $n$ variables be partially differentiable twice.

The necessary condition at the point $\boldsymbol{x}_{0}=\left[x_{10}, x_{20}, \ldots, x_{n 0}\right]^{\mathrm{T}}$ is that the partial differential function has to be zero

$$
\operatorname{grad} f\left(\boldsymbol{x}_{0}\right)=\left(\begin{array}{c}
\frac{\partial f}{\partial x_{1}} \\
\frac{\partial f}{\partial x_{2}} \\
\cdots \\
\frac{\partial f}{\partial x_{n}}
\end{array}\right)_{\underline{\boldsymbol{x}}=\underline{\boldsymbol{x}}_{0}}=\left(\begin{array}{c}
f_{x 1} \\
f_{x 2} \\
\cdots \\
f_{x n}
\end{array}\right)_{\underline{\boldsymbol{x}}=\underline{\boldsymbol{x}}_{0}}=\mathbf{0} .
$$

The minimum value at this point can be local minimum, maximum, or a saddle point. The type of the extremum can be characterized by the Hessian matrix. The Hessian matrix is as follows

$$
\mathrm{H}=\left[\begin{array}{cccc}
\frac{\partial^{2} f}{\partial x_{1} \partial x_{1}} & \frac{\partial^{2} f}{\partial x_{1} \partial x_{2}} & \cdots & \frac{\partial^{2} f}{\partial x_{1} \partial x_{n}} \\
\frac{\partial^{2} f}{\partial x_{2} \partial x_{1}} & \frac{\partial^{2} f}{\partial x_{2} \partial x_{2}} & \cdots & \frac{\partial^{2} f}{\partial x_{2} \partial x_{n}} \\
\ldots & \ldots & \ldots & \ldots \\
\frac{\partial^{2} f}{\partial x_{n} \partial x_{1}} & \frac{\partial^{2} f}{\partial x_{n} \partial x_{2}} & \cdots & \frac{\partial^{2} f}{\partial x_{n} \partial x_{n}}
\end{array}\right]=\left[\begin{array}{cccc}
f_{x_{1} x_{1}} & f_{x_{1} x_{2}} & \ldots & f_{x_{1} x_{n}} \\
f_{x_{2} x_{1}} & f_{x_{2} x_{2}} & \ldots & f_{x_{2} x_{n}} \\
\ldots & \ldots & \ldots & \ldots \\
f_{x_{n} x_{1}} & f_{x_{n} x_{2}} & \ldots & f_{x_{n} x_{n}}
\end{array}\right] .
$$

\section{The sufficient condition}

In the case the quadratic form of the Hessian matrix is positive definite at the $\boldsymbol{x}_{0}=\left[x_{10}, x_{20}, \ldots, x_{n 0}\right]^{\mathrm{T}}$ point, the result is a local minimum.

In the case the quadratic form of the Hessian matrix is negative definite at the $\boldsymbol{x}_{0}=\left[x_{10}, x_{20}, \ldots, x_{n 0}\right]^{\mathrm{T}}$ point, the result is a local maximum.

In the case the quadratic form of the Hessian matrix is indefinite at the $\boldsymbol{x}_{0}=\left[x_{10}, x_{20}, \ldots, x_{n 0}\right]^{\mathrm{T}}$ point, the result is a saddle point.

The suitable solving method for the optimizing problem can be selected depending on the actual form of the objective function and the constraints.

The next chapter will summarize historical development and classification of the optimum design methods. 


\section{Some tools of mathematical programming}

\subsection{Linear programing}

The linear optimization problem with restrictions seems to be an important special case of the optimization tasks. In this case, the objective function and all the restrictions are linear functions of the design variables. The simplex method of linear programming was developed by Dantzig in 1947 [5]. This method was successfully applied solving economic tasks, and also several technical problems became easy to solve. A lot of plastic deformation problems was modelled as linear optimum task, like beam or trust structures.

\subsection{Nonlinear programing}

The Lagrange multiplier method. In the case, when one of the functions of the system (1) is nonlinear, the optimum task is called nonlinear. Because of the majority of engineering problems are nonlinear, these methods have special importance. The problem can be formulated, to find the minimum of $f(\boldsymbol{x})$ to satisfy the $h_{j}(\boldsymbol{x})=0$ equality constraints $(j=1,2, \ldots, p)$, then the problem can be solved by the method of Lagrange (1736-1813). A so called Lagrange function was generated by adding the equality constraints to the objective function

$$
L\left(\boldsymbol{x}, \lambda_{j}\right)=f(\boldsymbol{x})+\sum_{j=1}^{p} \lambda_{j} h_{j}(\boldsymbol{x}),
$$

where the constants $\lambda_{j}$ are called Lagrange multipliers [6]. A location of the minimum and value of the modified main function can be obtained by using the methods developed for the unconstrained optimum tasks

$$
\begin{gathered}
\frac{\partial L\left(\boldsymbol{x}, \lambda_{j}\right)}{\partial x_{i}}=\frac{\partial f(\boldsymbol{x})}{\partial x_{i}}+\sum_{j=1}^{p} \lambda_{j} \frac{\partial h_{j}(\boldsymbol{x})}{\partial x_{i}}=0, \quad i=1,2, \ldots, n . \\
\frac{\partial L\left(\boldsymbol{x}, \lambda_{j}\right)}{\partial \lambda_{j}}=h_{j}(\boldsymbol{x})=0, \quad j=1,2, \ldots, p .
\end{gathered}
$$

The Lagrange multiplier rule can be used to convert an optimization problem with equality constraint into a nonlinear system of equations [7].

The method of Kuhn-Tucker criteria. This method has not been widely used by the middle of the 20 -th century even after its early development. The high capacity and high speed computers have made it possible to develop new methods and to apply the optimum calculation for different problems. A method was developed by Kuhn and Tucker for solving the problem (1) with inequality constraints in 1951 [8]. The method was widely used from the 60-es. According to this method, we have to find the minimum of the $f(\boldsymbol{x})$ main function, with the

$$
g_{j}(\boldsymbol{x}) \leqslant 0, \quad j=1,2, \ldots, m
$$

constraints. The $g_{j}(\boldsymbol{x})$ functions will be transformed into equality constraints by adding non-negative auxiliary variables $y_{j}^{2}$

$$
G_{j}\left(\boldsymbol{x}, y_{j}\right)=g_{j}(\boldsymbol{x})+y_{j}^{2}=0, \quad j=1,2, \ldots, m .
$$

The modified optimum task can be solved using the Lagrange method as follows. The Lagrange function

$$
L\left(\boldsymbol{x}, y_{j}, \lambda_{j}\right)=f(\boldsymbol{x})+\sum_{j=1}^{m} \lambda_{j} G_{j}\left(\boldsymbol{x}, y_{j}\right) .
$$


The necessary condition of the local minimum is

$$
\begin{gathered}
\frac{\partial L}{\partial x_{i}}=\frac{\partial f(\boldsymbol{x})}{\partial x_{i}}+\sum_{j=1}^{m} \lambda_{j} \frac{\partial g_{j}(\boldsymbol{x})}{\partial x_{i}}=0, \quad i=1,2, \ldots, n, \\
\frac{\partial L}{\partial \lambda_{j}}=g_{j}(\boldsymbol{x})+y_{j}^{2}=0, \quad j=1,2, \ldots, m \\
\frac{\partial L}{\partial y_{j}}=2 \lambda_{j} y_{j}=0, \quad j=1,2, \ldots, m
\end{gathered}
$$

In the case of active constraints $g_{j}=0$, then $y_{j}=0$, and $\lambda_{j} \geqslant 0$. When the constraints are inactive, $g_{j}<0$, then $y_{j} \neq 0$ and $\lambda_{j}=0$. Thus, instead of (10) and (11) we can use the

$$
\lambda_{j} \geqslant 0 \quad \text { and } \quad \lambda_{j} g_{j}=0
$$

conditions in the case of active constraints.

The conditions of

$$
\begin{gathered}
\frac{\partial f(\boldsymbol{x})}{\partial x_{i}}+\sum_{j=1}^{m} \lambda_{j} \frac{\partial g_{j}(\boldsymbol{x})}{\partial x_{i}}=0, \quad i=1,2, \ldots, n, \\
\lambda_{j} \geqslant 0 \quad \text { and } \quad \lambda_{j} g_{j}=0
\end{gathered}
$$

are called Kuhn-Tucker optimum criteria [9]. When the set of feasible points forms a convex range, the Kuhn-Tucker criteria are the necessary and sufficient conditions of the existence of the global minimum.

SUMT (Sequential Unconstrained Minimization Techniques) method. The major cases of technical problems the objective (main) function as well as the restriction functions are nonlinear functions of the design variables, so the optimization problem can be handled by the methods of nonlinear optimization. One of the most well-known nonlinear optimization methods is the Sequential Unconstrained Minimization Technique (SUMT) - method. The essence of this method is transferring the problem with restrictions into a problem without restrictions. A designer often meets optimization tasks with several target functions during the product optimization process. The optimization task with several target functions represents an aggravation of the optimization problem. Because of the various application possibilities, an intensive development can be observed last years.

The first overview about the modern engineering optimization was made by Schmit [10], who applied the mathematical programming method for designing elastic structures under difficult load cases, subjected to nonlinear inequality constraints. Also we have to mention, that a new design philosophy was established in the engineering practice and had a great role to introduce the finite element method and the nonlinear programming into the automated optimum design method. A strong development of the nonlinear optimization was started, when - based on the study of Caroll [11] Fiacco and McCormick [12] developed the sequential unconstrained minimization method (SUMTmethod). The SUMT method transfers the (1) constrained optimum task to an unconstrained set of minimization tasks of the $P\left(\boldsymbol{x}, r_{k}\right)$ function

$$
P\left(\boldsymbol{x}, r_{k}\right)=f(\boldsymbol{x})-r_{k} \sum_{j=1}^{m} \ln g_{j}(\boldsymbol{x})+r_{k}^{-1} \sum_{j=m+1}^{p}\left\{\min \left[0, h_{j}(\boldsymbol{x})\right]\right\}^{2},
$$

where the convergence speed depends on the initial value $r_{1}$ of the $r_{k}$ parameter. The value of $r_{k}$ will be monotone decreasing

$$
\begin{gathered}
r_{1}>r_{2}, \ldots,>0, \quad r_{k+1}=r_{k} / c, \quad c>1, \\
\lim \left[\min P\left(\boldsymbol{x}, r_{k}\right)\right]=\min f(\boldsymbol{x}) .
\end{gathered}
$$


It is easy to show, that in the case of $r_{k} \rightarrow 0$, the set of the minimum values of the unconstrained optimum task will converge to the solution of the constrained $f(\boldsymbol{x})$ function.

In order to understand the method, a sample task will be shown in the following chapter.

\subsection{Multi-objective optimization}

Multi-objective optimization is a vector optimization, each element of which represents one of the objective functions being optimized. Effective methods for multi-objective optimization are listed below:

The multi-objective optimization is widely used for solving optimization tasks of engineering problems [13-14]. The method was developed by Vilfredo Pareto (1848-1923). The method was published in 1896. The Pareto optimum is a solution point, where no other main function can be improved without the degradation of another main function. We cannot find too many papers about the theory of the multi-objective optimization by the 60-es, but a lot of papers came out in this topic after that, including also the decision making applications. Mathematical formulation is as follows

$$
\begin{gathered}
\min F(\boldsymbol{x})=\left[f_{1}(\boldsymbol{x}), \ldots, f_{n}(\boldsymbol{x})\right], \quad n=1,2, \ldots, \\
0 \leqslant g_{j}(\boldsymbol{x}), \quad j=1,2, \ldots, m, \\
0=h_{j}(\boldsymbol{x}), \quad j=m+1, \ldots, m,
\end{gathered}
$$

where $f_{i}(\boldsymbol{x})$ is the $i$-th objective function; $g_{j}(\boldsymbol{x}), h_{j}(\boldsymbol{x})$ are the inequality as well as the equality constraints. All of these functions or some of them can be nonlinear. We have several methods for solving the problem. We are describing here so called weighting method. We apply here the $w_{i}$ weight factors for the different main functions and a new main function is formulated here [15-16]

$$
F(\boldsymbol{x})=\sum_{i=1}^{n} w_{i} f_{i}(\boldsymbol{x}),
$$

where $\sum_{i=1}^{n} w_{i}=1$ and $w_{i} \geqslant 0$.

The weight factors have to be selected based on the importance of the single main functions.

\subsection{Evolutionary optimization method}

Recently, the evolutionary algorithms are used frequently as optimization procedures in the case of component and product optimization (mechanical components) [17].

Evolutionary algorithms are stochastic search methods, which are based on the principles of the biological evolution. Three optimization directions of the evolutionary algorithms were developed independently from each other: the evolutionary programming, the evolution strategies, and the genetic algorithms. All these methods use the variation and selection operations as the basic elements of the evolution process, but they differ in the development of these elements [18]. The usage of these algorithms is going to increase in the coming years due to the various application possibilities. The calculation of the actual restriction values (e.g. shifts, tensions, etc.) can be computed in many applications only by numeric methods.

\subsection{Some nature-inspired heuristic algorithms}

The heuristic algorithms are based on an observation of a natural phenomenon. The algorithm was developed on the behaviour of different animals. Some of them are described below $[19,20]$.

The Particle Swarm algorithm (PSO) was developed in 1995; it is the most promising metaheuristic optimizing method. The PSO is based on the food searching motion of bird flocking or fish schooling. 
The operation of the method starts with the generation of numerous particles locates randomly selected starting points. The particles are moving together to other places providing better solutions for the problem, and the squad motion is driven by the best animal. The algorithm based on the nutrition of bacteria (Bacterial Foraging - BA) was first published in 2002, and it is working on the phenomenon of the squad intelligent. The common characteristics of these methods, that the behaviour model of a large population is replicated. If an individual creature is not able to solve the problem, the collective intelligence of a group could be enough for solving the problem according to the phenomena. The Firefly (FF) algorithm was first developed by Xin-She Yang in late 2007. The phenomena of this method originated from the firefly-type creatures. These insects find each other with the help of special light emission. The better solution was found by one bug, the stronger light will be submitted. This strong light emission will pull the others to that area. The Ant Colony algorithm is based on the observation of the nutrition of ant colonies. The random route searching will be systematic by indicating the way with the feromon tracks, after finding the food.

\section{Technical optimization problems}

A lot of optimization problem will combine technical and economical requirements against the product or the component, so functional and economical requirements must be equally considered. When specifying the technical and economical approaches, product and process optimization are defined. The product optimization can be specified as follows [21,22]:

product optimization:

- topology optimization,

- form optimization,

- dimension optimization,

- material optimization and

process optimization.

During the topology optimization, the arrangement of geometrical elements of a product can be determined (dimensions and position) with the optimizing procedure (Fig. 3). The topology optimization is an everyday task of technical designers. They have to design a component (as a part of a product) so that available space must not exceed, it has to keep the outside loads, and the minimum material expenditure can be achieved at the same time [23].
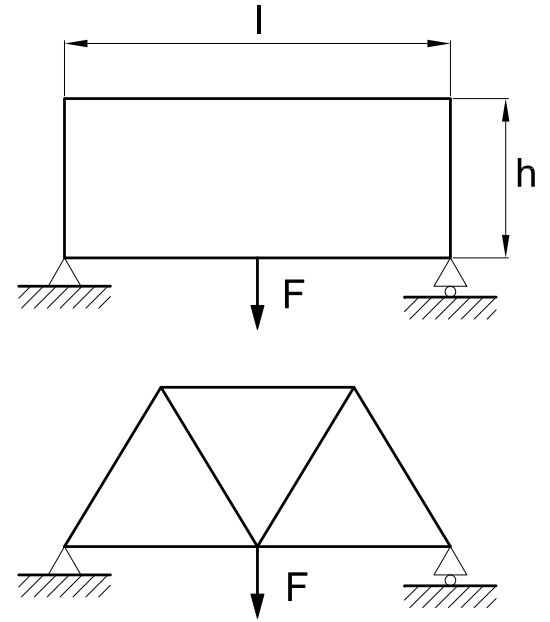

Fig. 3. Topology optimization.
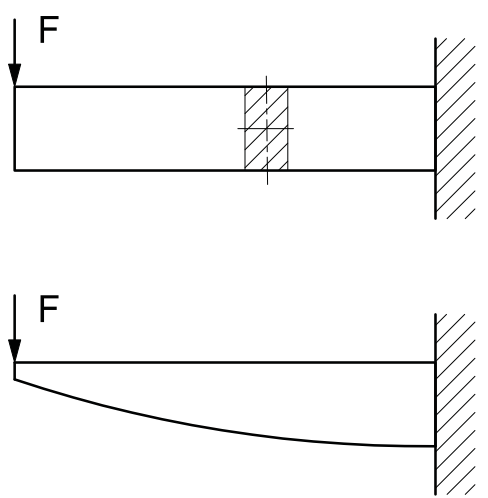

Fig. 4. Form optimization of beam.

During the beam unit optimization, the topology optimization is an effective design tool, because it is possible to develop light and at the same time rigid beam units [24]. As an initial geometry, 
the results of the topology optimization can be usually used for the dimension and form optimization process.

A goal of the form optimization is to determine the optimal geometry of a construction - under given boundary conditions - regarding defined quality criteria (Fig.4). Objective function and restrictions are selected according the nature of the tasks [25].

In the case of dimension optimization, the dimensions of cross sections are often computed [26-27]. In the cross-sectional optimization problems mainly displacements, tensions or natural frequencies are determined (Fig. 5). An example of this class of optimization problems is the calculation of optimal dimensions of mechanical components or the optimization of the isolation thickness of pipelines [28].

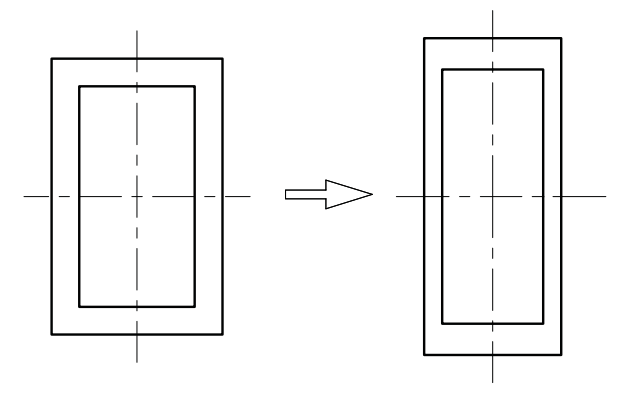

Fig. 5. Dimensional optimization of a rectangular section.

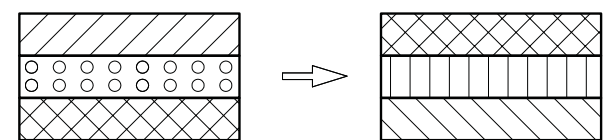

Fig. 6. Material optimization of a composite structure.

During the material optimization have to find the optimal structure of the materials [21] e.g. how to arrange the structure of Composite layers (Fig. 6) or how to arrange the fiber strips in fiber-reinforced materials.

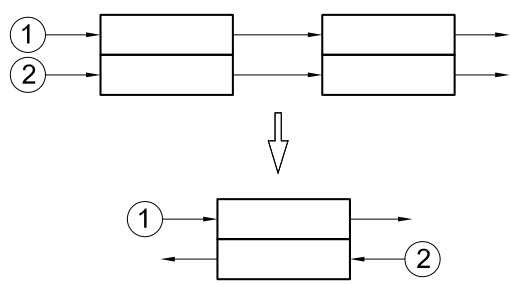

Fig. 7. Process optimization in the heat transfer technology.
The material optimization basically is a topology optimization, however, in the variable space is a microscopic solution area.

The process optimization was developed in technology and economics in the last decades very rapidly, and the theory was based on the discipline "Operation's Research". The technical processes in the production were completed with the disassembly or the recycling, the technological processes with the equipment technology (Fig. 7) or economic processes in the economic science models.

\section{Optimal design of railway bogie}

The railway bogie is a heavy duty sub-assembly of carriage, bearing the weight of the payload, the dead load of all the rest of the carriage assembly as well as the dynamic loads originated from the normal or the exceptional operation. We are going to find the optimal dimensions of a welded, box type freight bogie, which will minimize the total manufacturing cost of the structure and will satisfy several engineering conditions originated from the strength level, or from manufacturing issues.

\subsection{Geometrical model}

The geometrical model of the bogie is, basically, a H-type structure with double main frame as it is illustrated in Fig. 8. Both the side and the main beams are modelled as prismatic, welded box beams. In order to increase the overall rigidity of the structure, all the beams are reinforced by welded diaphragms in certain cross sections [29]. 

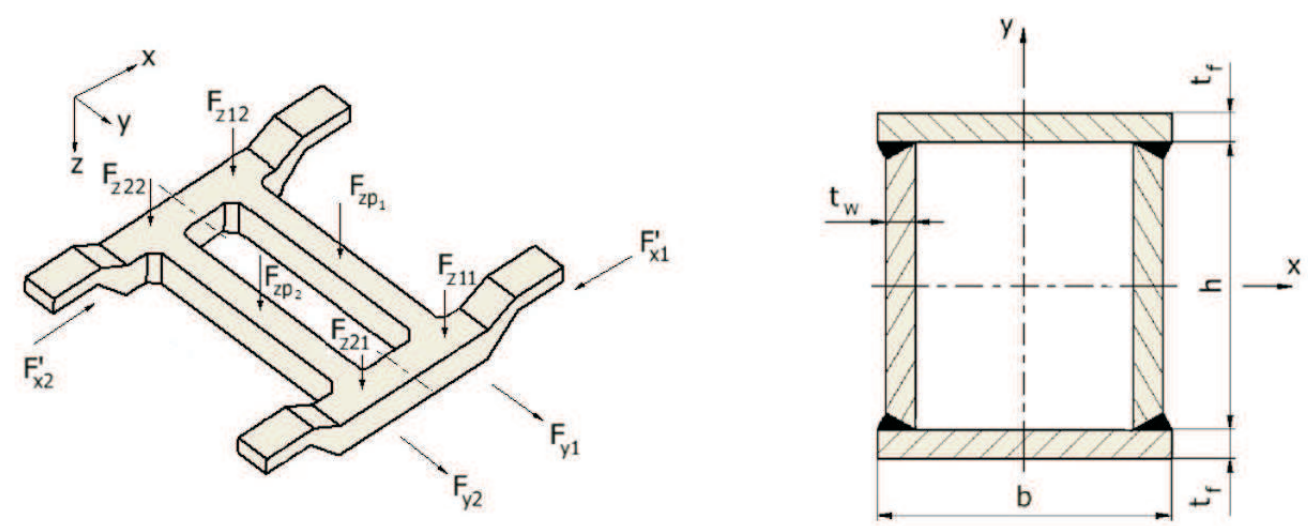

Fig. 8. Schematic geometric model, loads, and cross section of the bogie frame.

\subsection{External loads and supports}

The external loads (forces) originated from the normal and exceptional operation of the vehicle, and have to be calculated according to the rules described in the EN 13749 norm. Different load cases are defined here based on special operating conditions. The location and direction of the external loads are also described in Fig. 9.

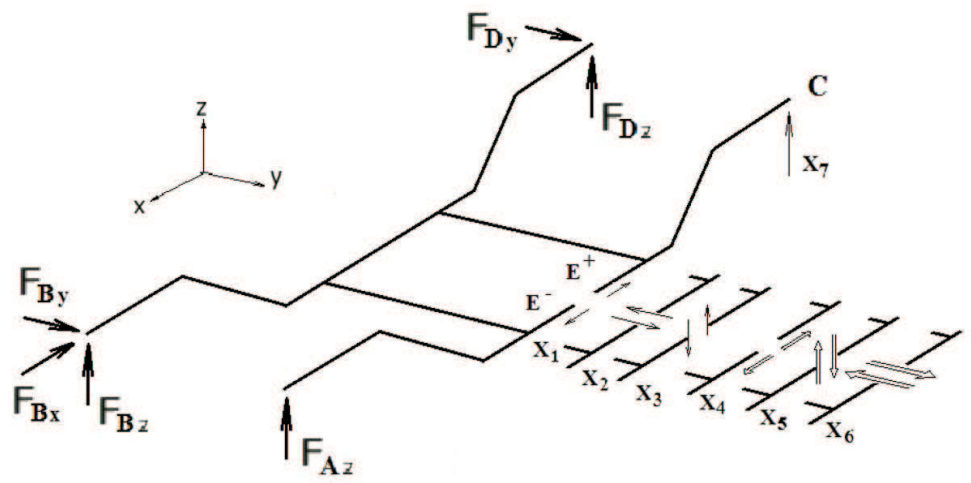

Fig. 9. Statically determined structure and additional loads.

\subsection{Internal loads and mechanical stresses}

$F_{z}, F_{y}$, and $F_{x}$ are the external loads, acting on the beam structure. $F_{z}$ originated from the dead loads, $F_{y}$ from the wind load and the additional load running in curved rail, and $F_{x}$ from the operation of the train.

Because of the number of reaction forces of the structure are larger than the number of static equilibrium equations, it is said the structure is statically indeterminate. Moreover, the closed frame design will make us to establish more static constraints to calculate the reactions.

The statically indeterminate structure has to be converted to a statically determinate primary structure acted upon by the external loads and secondary structures acted upon by the redundancies. The deformations (deflection or rotation) corresponding to the selected redundancies are determined from the boundary and the continuity conditions.

The vertical displacement at the point " $\mathrm{C}$ " is zero, the displacements and the deflections at the point "E" are equals (the displacement field is continuous at the point "E")

$$
\delta_{i}^{E^{-}}-\delta_{i}^{E^{+}}=0, \quad i=1, \ldots, 6 .
$$


In this case, seven redundancies (support force at "C" and internal loads at "E") have to be calculated from a system of seven equations. Equation system for calculating the $X_{1}, \ldots, X_{7}$ internal loads [28]

$$
\left[\begin{array}{ccccccc}
\cdots & \ldots & \ldots & \ldots & \ldots & \ldots & \ldots \\
\cdots & \ldots & \ldots & \ldots & \ldots & \ldots & \ldots \\
\cdots & \ldots & \delta_{k i} & \ldots & \ldots & \ldots & \delta_{7 i} \\
\ldots & \ldots & \ldots & \ldots & \ldots & \ldots & \ldots \\
\cdots & \ldots & \ldots & \ldots & \ldots & \ldots & \ldots \\
\cdots & \ldots & \ldots & \ldots & \ldots & \ldots & \ldots \\
\cdots & \ldots & \delta_{k 7} & \ldots & \ldots & \ldots & \delta_{77}
\end{array}\right]\left[\begin{array}{c}
\ldots \\
\ldots \\
X_{i} \\
i=1, \ldots, 6 \\
\ldots \\
\ldots \\
\ldots \\
X_{7}
\end{array}\right]=-\sum_{k=x, y, z}\left[\begin{array}{c}
\cdots \\
\ldots \\
\delta_{01}^{k} \\
\ldots \\
\ldots \\
\ldots \\
\delta_{07}^{k}
\end{array}\right] F_{k},
$$

where the

$$
\delta_{i j}=\delta_{i j}^{E^{-}}-\delta_{i j}^{E^{+}}=0, \quad(i, j=1, \ldots, 6) .
$$

coefficients means displacement (deflection) difference in direction " $j$ ", at the points $E^{-}$and $E^{+}$due to the internal load $X_{i}$.

The displacements (deflections) at the point $P$ were calculated from the principle of virtual work using the $N_{z}, M_{x}, M_{y}, M_{z}$ load diagrams originated from the load acting at the point $P$ in direction " $i$ ", and also the $N_{z}^{*}, M_{x}^{*}, M_{y}^{*}, M_{z}^{*}$ load diagrams originated from the unit load acting at the point Q in direction " $j$ ".

The integrals were calculated using the Simpson formula. Altogether 19 elements and 57 points were established on the bogie frame for the numerical calculations.

The topology of the bogie frame was built up from welded box beams reinforced at selected locations. The height of the web plates are uniform in the middle area of the frame (main beams and for the side beams).

Also the height of the web plate is uniform at the end sections. The dimension of the flange plate was uniform for all the side beams as well as for the main beams.

The plate thicknesses for the side beams and for the main beams are uniform.

A matrix formulation was used for handling all of the internal loads, displacements, etc.

The vector of the design variables (the unknowns to be calculated) is following:

$$
\mathbf{T}^{\mathrm{T}}(i)=\left[\begin{array}{llllllll}
h_{1} & h_{2} & b_{m} & b_{s} & t_{m, w} & t_{m, f} & t_{s, w} & t_{s, f}
\end{array}\right] .
$$

Where $h_{1}$ is the height of the side beams in the middle section and the main beams, $h_{2}$ is the height of the side beams at the ends, $b_{m}$ is the dimension of the flange plate for the main beams, $b_{s}$ is the dimension of the flange plate for the side beams, $t_{m, w}$ and $t_{s, w}$ are the plate thickness of the web and side plates for the main beam, $t_{m, f}$ and $t_{s, f}$ are the plate thickness of the web and side plates for the main beam (Fig. 10).

The topology matrix $(\mathbf{A}(57,6))$ will describe the structure of the frame for each cross sections (for 57 cross sections according to Fig. 11). The first column denotes if the cross section is reinforced (1) or not (0). The dimension $s_{r}$ is the characteristic dimension (thickness) of the reinforcement

$$
\mathbf{A}(57,6)=\left[\begin{array}{cccccc}
0 & T(2) & T(7) & T(4) & T(8) & 0 \\
1 & T(2) & T(7) & T(4) & T(8) & s_{p} \\
\ldots & \ldots & \ldots & \ldots & \ldots & \ldots \\
0 & \frac{T(1)+T(2)}{2} & T(7) & T(4) & T(8) & 0 \\
\ldots & \ldots & \ldots & \ldots & \ldots & \ldots \\
0 & T(1) & T(5) & T(3) & T(6) & 0 \\
\ldots & \cdots & \cdots & \ldots & \ldots & \ldots
\end{array}\right]
$$



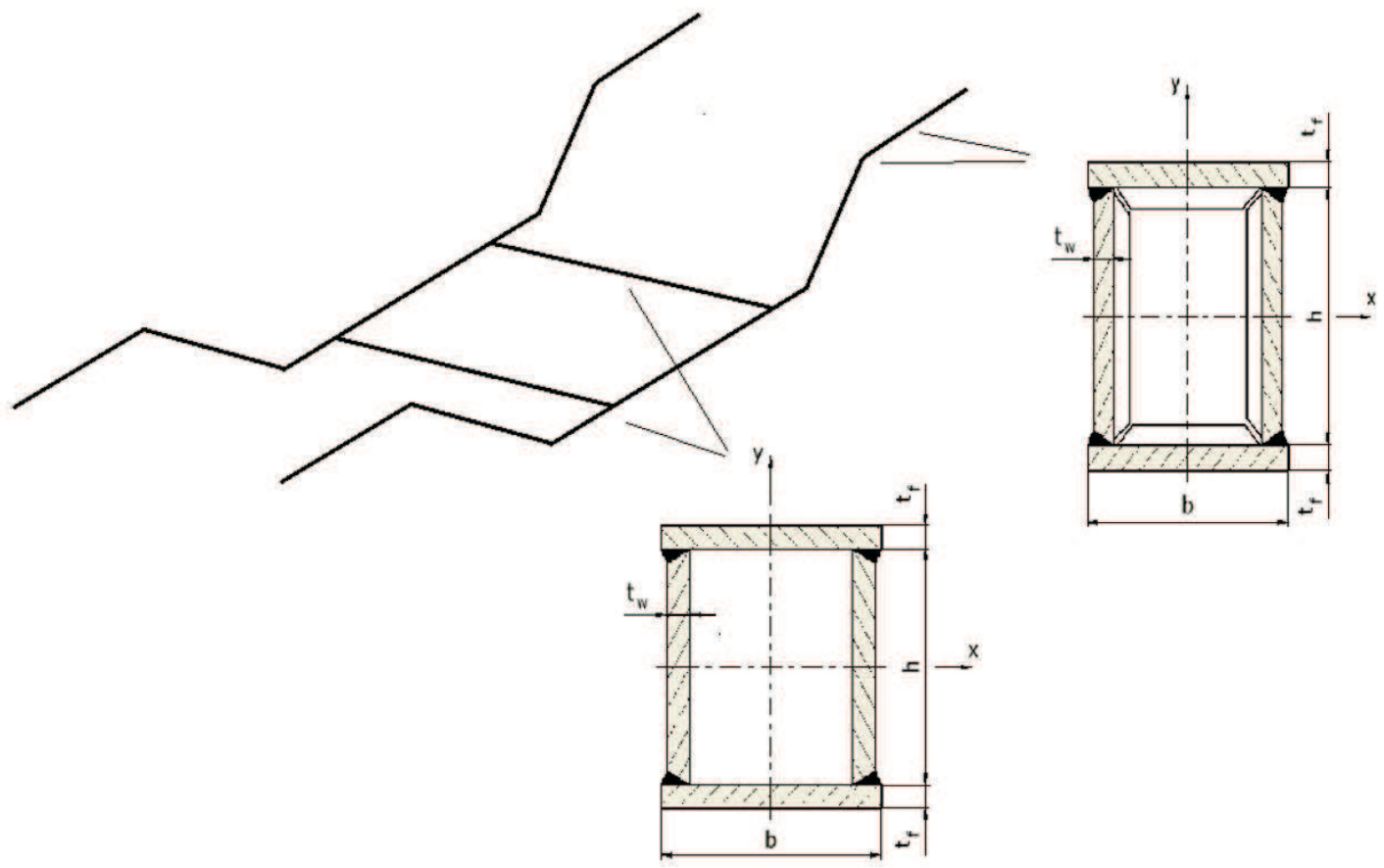

Fig. 10. Topology of the bogie structure.

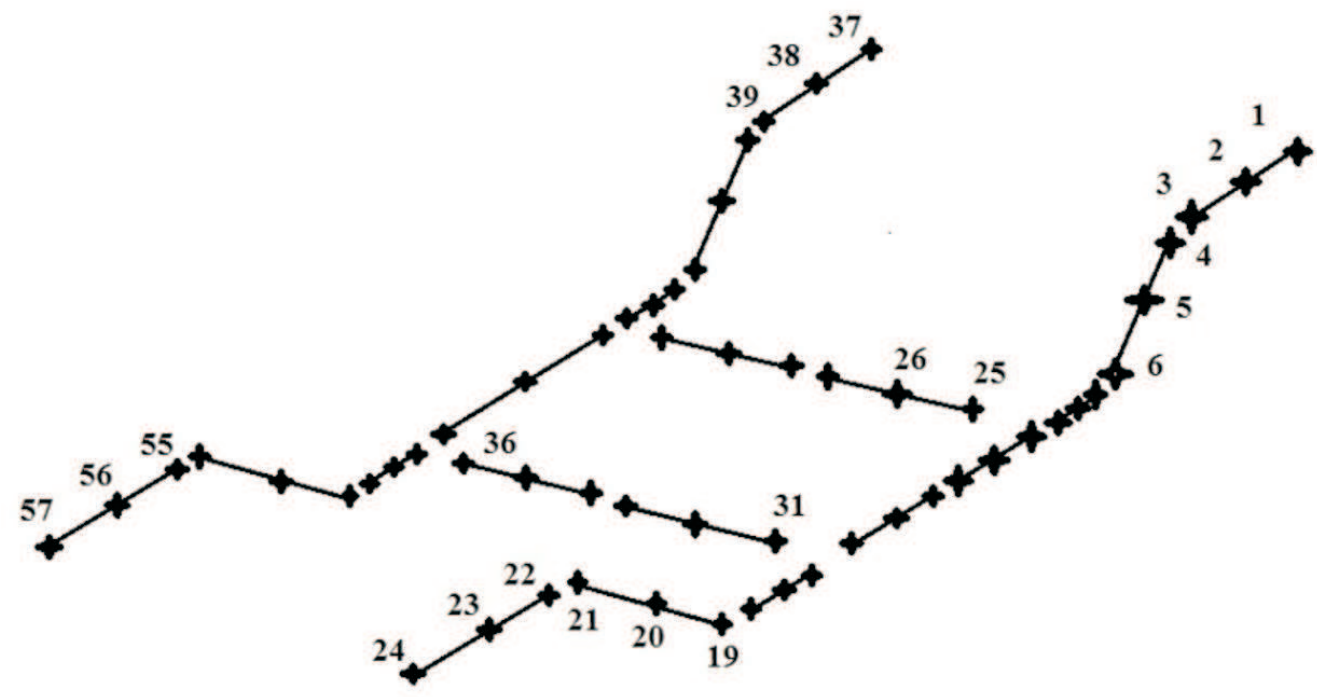

Fig. 11. Nodes for calculation of mechanical stresses.

The geometry matrix $\mathbf{G}(57,10)$ contains the length, cross section, inertia of each cross sections (for 57 cross sections). If the cross section is reinforced, the $7-10$-th columns contain the geometrical data for the reinforced sections [29]

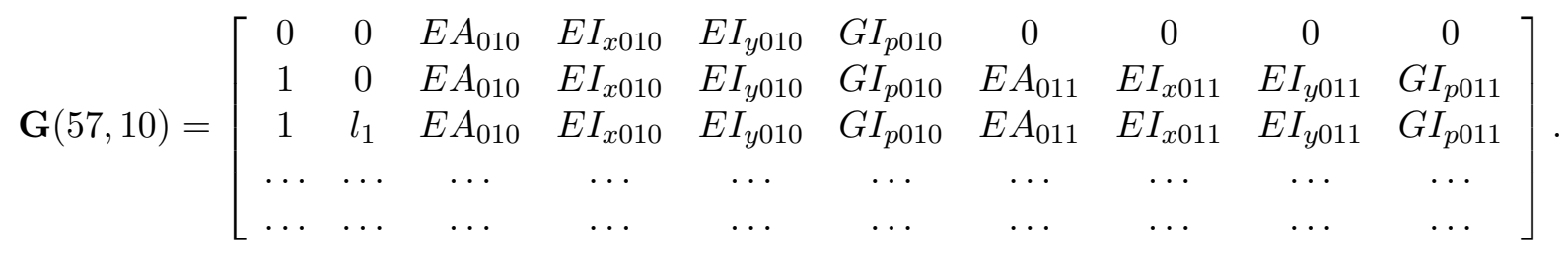


The external load matrices $\left(F_{x}, F_{y}, F_{z}\right)$ contain the tension load, the shear forces, the bending moments and the twisting moment for all the 57 cross sections. The load matrices were generated for all the components of the external forces $\left(F_{x}, F_{y}, F_{z}\right)$ and for all the components of the $X_{1}^{+}, X_{1}^{-}, \ldots$, $X_{7}$ internal and support forces. A sample for $F_{x}$

$$
F_{x}(57,6)=F_{x}\left[\begin{array}{cccccc}
-1 & 0 & 0 & 0 & 0 & 0 \\
-1 & 0 & 0 & 0 & 0 & 0 \\
-1 & 0 & 0 & 0 & 0 & 0 \\
-\cos \alpha & 0 & 0 & 0 & 0 & 0 \\
-\cos \alpha & \sin \alpha & 0 & h / 2 & 0 & 0 \\
\ldots & \ldots & \ldots & \ldots & \ldots & \ldots
\end{array}\right] .
$$

The final internal force matrix $(\mathbf{L}(57,6))$ was calculated as a summary of the internal forces originating from the external $\left(F_{x}, F_{y}, F_{z}\right)$ and internal $\left(X_{1}, \ldots, X_{7}\right)$ forces

$$
\mathbf{L}(57,6)=\left[\begin{array}{cccccc}
\cdots & \cdots & \cdots & \cdots & \cdots & \cdots \\
\sum_{F_{i}, X_{i}} N_{i} & \sum_{F_{i}, X_{i}} T_{1, i} & \sum_{F_{i}, X_{i}} T_{2, i} & \sum_{F_{i}, X_{i}} M_{B 1, i} & \sum_{F_{i}, X_{i 7}} M_{B 2, i} & \sum M_{T 3, i} \\
\cdots & \cdots & \cdots & \cdots & \cdots & \cdots
\end{array}\right]
$$

The mechanical stress matrix $\boldsymbol{\sigma}(57,6)$ was calculated using the formulas of the elasticity

$$
\boldsymbol{\sigma}(57,7)=\left[\begin{array}{ccccccc}
\ldots & \ldots & \ldots & \ldots & \ldots & \ldots & \ldots \\
\sigma_{\max , N} & \tau_{\max , T_{1}} & \tau_{\max , T_{2}} & \sigma_{\max , M_{B 1}} & \sigma_{\max , M_{B 2}} & \tau_{\max , M_{T 1}} & \tau_{\max , M_{T 2}} \\
\cdots & \ldots & \ldots & \ldots & \ldots & \ldots & \ldots
\end{array}\right] .
$$

\subsection{Cost function}

The target of the optimization process is to find the best set of the design variables which will minimize the total manufacturing cost of the bogie frame covering the material cost and all the production process related costs [29]

$$
K=k_{m} \rho V+k_{f}\left(T_{1}+T_{2}+T_{3}+T_{4}+T_{5}+T_{6}+T_{7}\right),
$$

where $k_{m}$ is the material cost and $k_{f}$ is the fabrication cost, $\rho$ is the density, $V=\Sigma 2\left(b_{i} t_{f i}+h_{i} t_{w i}\right) l_{i}$ is the total volume of the structure, $l$ is the length of bogie, and $T_{i}$ is the fabrication time for the $i$-th operation.

Fabrication times for the preparation, assembly, and tacking. $T_{1}$ is the preparation, assembly, and tacking time, can be formulated with an approximation equation [30]

$$
T_{1}=C_{1} \Theta_{d} \sqrt{\kappa \rho V}
$$

where $C_{1}$ is a welding technology dependent constant, $\theta_{d}$ is a difficulty factor and $\kappa$ is the number of structural components to be assembled.

Real welding time and additional action time. The real welding time depends on the length of the weld and on the weld size. The time for additional actions will cover the time consumption for changing the electrodes, deslagging and chipping [30]

$$
T_{2}+T_{3}=1.3 \sum_{1}^{n} C_{2 i} a_{w i}^{1.5} L_{w i}
$$


where $C_{2 i}$ is the $i$-th welding technology dependent constant factor, $a_{w i}$ is the $i$-th weldsize and $L_{w i}$ is the $i$-th weld length.

Plate flattening time. Prior to assembling together the web and flange plates it is necessary to make them flat. The time for the plate flattening will be the function of the plate thickness $t$ and the total area of the plates $A_{p}=2\left(b_{l}+h_{l}\right)$. Based on industrial practice, the time necessary for the plate flattening is as follows [30]:

$$
T_{4}=\Theta_{d e}\left(a_{e}+b_{e} t^{3}\right) A_{p}
$$

where $\theta_{d e}$ is the difficulty factor for plate flattening, $a_{e}$ and $b_{e}$ are constants.

Surface preparation time. The surface preparation time means the cleaning (rust removal, degreasing) of the surfaces prior the painting operation. It will depend on the surface area $A_{p}=4\left(b_{l}+h_{l}\right)$

$$
T_{5}=\Theta_{d s} a_{s p} A_{p}
$$

where $\theta_{d s}$ is the difficulty factor for surface preparation, $a_{s p}$ is a parameter [29].

Painting time. The painting operation generally means to prepare a two layer protection film (ground coat and finishing coat). The structure of the time function is similar to the preparation. It will depend on the surface area $A_{p}[30]$

$$
T_{6}=\Theta_{d p}\left(a_{g c}+a_{t c}\right) A_{p}
$$

where $\theta_{d p}$ is the difficulty factor, $a_{g c}$ and $a_{t c}$ are parameters.

Time of plate cutting and edge grinding. The time necessary for the plate cutting and edge grinding will be the function of the plate thicknesses $t$ and the length of the cut $L_{c i}=2(h+l)$ and $L_{c i}=2(b+l)$, respectively, [29]

$$
T_{7}=\sum_{i=1}^{n} C_{7 i} t_{i}^{n} L_{C i},
$$

where the $C_{7 i}$ parameter depends on the cutting technology, $n$ is a parameter, $t=t_{w}$ and $t=t_{f}$, respectively.

\subsection{Design variables}

The design variables (unknowns to be optimized) in the calculation process are the $h, b, t_{w}$ and $t_{f}$ dimensions of the each beam elements according to the design restrictions, which will be described later. The plate thickness for the side and main panels are considered to be uniform from technological point of view. The total number of the design variables (the number of dimension of the design space) is eight.

\subsection{Design constraints}

Static and fatigue stress limitation constraint. The maximal equivalent stress must not exceed the material specific admissible stress $\sigma_{a d m}$

$$
\sigma_{\max }=\sigma_{e q} \leqslant \sigma_{a d m},
$$

where

$$
\sigma_{e q}=\max \left(\sigma_{v M i s e s 1}, \sigma_{v M i s e s 2}\right)
$$


and

$$
\begin{aligned}
& \sigma_{v M i s e s 1}=\sqrt{\left(\sigma_{N}+\sigma_{M B 1}+\sigma_{M B 2}\right)^{2}+3\left(\tau_{T_{1}}+\tau_{M_{T 1}}\right)^{2}}, \\
& \sigma_{v M i s e s 1}=\sqrt{\left(\sigma_{N}+\sigma_{M B 1}+\sigma_{M B 2}\right)^{2}+3\left(\tau_{T_{2}}+\tau_{M_{T 2}}\right)^{2}}
\end{aligned}
$$

the stress data are taken from the $\boldsymbol{\sigma}(57,7)$ matrix.

Fatigue stress constraint based on Eurocode 3.

$$
\gamma_{F f} \Delta \sigma \leqslant \Delta \sigma_{L} / \gamma_{M f}
$$

where $\gamma_{F f}$ is a safety factor, $\Delta \sigma=\sigma_{\max }-\sigma_{\min }$, the nominal stress range, $\gamma_{M f}$ is the fatigue safety factor for the $\Delta \sigma_{L}$ stress, $\Delta \sigma_{L}$ is the cut-off limit for $10^{8}$ cycle.

Buckling condition for the web and the flange plate. The relevant condition for the web and flange plate was calculated following the methodology of the Eurocode 3.

The buckling limitation for the flange is

$$
\beta_{w} h \leqslant t_{w}
$$

where $\beta_{w}=1 /(124 \varepsilon), \varepsilon=\left(235 / f_{y}\right)^{1 / 2}$ according to the Eurocode 3 , and $f_{y}$ is the yield stress.

The buckling limitation for the flange is

$$
\delta_{f} b \leqslant t_{f}
$$

where

$$
\delta_{f}=1 /(42 \varepsilon) .
$$

Also the effect of the reinforcements, applied to several cross sections of the side beams and also the main beams were considered.

Dimensional constraints. The following dimensional constraints were applied for the thickness of the web plates and the flange plates:

$$
\begin{gathered}
8 \leqq t_{f} \leqq 15[\mathrm{~mm}], \quad 8 \leqq t_{w} \leqq 15[\mathrm{~mm}], \\
150 \leqq b \leqq 250[\mathrm{~mm}], \quad 150 \leqq h \leqq 300[\mathrm{~mm}] .
\end{gathered}
$$

\subsection{Numerical results}

The mathematical optimizing task was solved using the modified SUMT (Sequential Unconstrained Minimization Technique) method for 5 different load cases according to the EN 13749. The load cases are described in Table 1.

Table 1. Load cases of the optimization.

\begin{tabular}{|c|c|c|c|c|}
\hline Load case & $F_{z 1}[\mathrm{kN}]$ & $F_{z p}[\mathrm{kN}]$ & $F_{z 2}[\mathrm{kN}]$ & $F_{y}[\mathrm{kN}]$ \\
\hline 1 & 0 & 372 & 0 & 0 \\
\hline 2 & 0 & 446 & 0 & 0 \\
\hline 3 & 0 & 298 & 0 & 0 \\
\hline 4 & 89 & 357 & 0 & -4.4 \\
\hline 5 & 60 & 238 & 0 & -4.4 \\
\hline
\end{tabular}

Mathematical Modeling and Computing, Vol. 3, No. 1, pp. 59-78 (2016) 
Numerical data for the calculation: $k_{m}=3 \mathrm{USD} / \mathrm{kg} ; k_{f}=50 \mathrm{USD} / \mathrm{hour} ; \rho=7.85 \cdot 10^{-6} \mathrm{~kg} / \mathrm{mm}^{3}$; $C_{1}=1 ; \theta_{d}=2 ; C_{2 i}=0.7889 \cdot 10^{-3} ; a_{w i}=t_{w} ; L_{w i}=1435 \mathrm{~mm} ; \theta_{d e}=1.2 ; a_{e}=9.2 \cdot 10^{-4} \mathrm{~min} / \mathrm{mm}^{2} ;$ $b_{e}=4.15 \cdot 10^{-7} \min / \mathrm{mm}^{5} ; \theta_{d s}=1.2 ; a_{s p}=3 \cdot 10^{-6} \mathrm{~min} / \mathrm{mm}^{2} ; \theta_{d p}=1.2 ; a_{g c}=3 \cdot 10^{-6} \mathrm{~min} / \mathrm{mm}^{2} ;$ $a_{t c}=4.15 \cdot 10^{-6} \mathrm{~min} / \mathrm{mm}^{2} ; C_{7 i}=0.691 ; n=0.383 ; \sigma_{a d m}=220 \mathrm{MPa} ; \tau_{a d m}=140 \mathrm{MPa} ;(\mathrm{S} 275 \mathrm{steel})$; $g_{F f}=1 ; g_{M f}=1.35 ; \Delta \sigma_{L}=51 \mathrm{MPa} ; \Delta \tau_{L}=46 \mathrm{MPa} ; f_{y}=275 \mathrm{MPa}$; welding technology: manual arc welding.

The results of the optimizing process (the minimum cost for each load cases as well as the optimum values of the design parameters) are described in Table 2.

Table 2. Optimum results.

\begin{tabular}{|c|c|c|c|c|c|c|c|c|c|}
\hline $\begin{array}{c}\text { Number } \\
\text { of load case }\end{array}$ & $\begin{array}{c}\text { Minimum } \\
\text { of cost function [USD] }\end{array}$ & \multicolumn{8}{|c|}{ Optimal } \\
\hline No. & $K_{\min }$ & $h_{1}$ & $h_{2}$ & $b_{m}$ & $b_{s}$ & $t_{m, w}$ & $t_{m, f}$ & $t_{s, w}$ & $t_{s, f}$ \\
\hline 1 & 8244 & 300 & 290 & 150 & 150 & 11.1 & 8.0 & 12.2 & 8.5 \\
\hline 2 & 9924 & 290 & 290 & 150 & 150 & 13.5 & 8.4 & 12.1 & 8.5 \\
\hline 3 & 6696 & 290 & 290 & 150 & 150 & 8.7 & 8.0 & 12.3 & 8.5 \\
\hline 4 & 8028 & 298 & 300 & 151 & 150 & 10.5 & 9.2 & 12.5 & 8.5 \\
\hline 5 & 5724 & 251 & 240 & 150 & 150 & 8.0 & 8.0 & 12.2 & 8.5 \\
\hline
\end{tabular}

The results after the optimization show, that it is possible to find an economic (from engineering point of view: optimal) design to gain the maximum benefit and to cause the minimum negative impact on the natural and economic environment. Also several engineering constraints were fulfilled; among them are fatigue stress limitation and local buckling criteria of the web and flange plates.

The effectivity of the calculation method can be characterized by the convergence history graph. The algorithm converges very fast after some $\sim 100$ steps, and will reach optimum value after $150-200$ iteration steps.

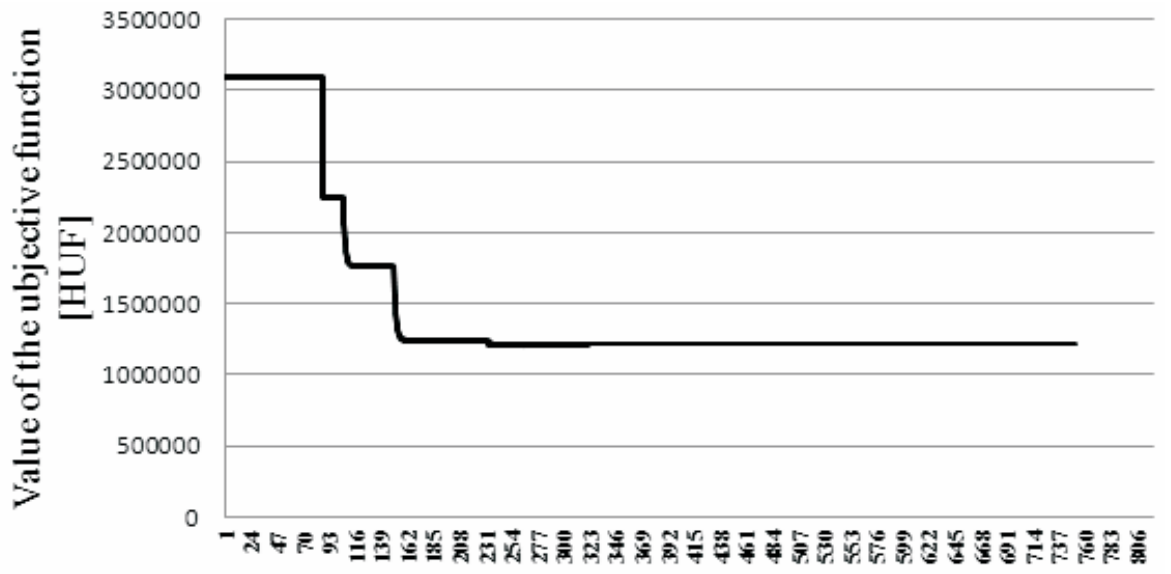

Fig. 12. Convergence history of objective function.

\section{Optimization of insulation layer thickness for pipelines}

\subsection{The thermal resistances of cylindrical wall}

The conductive thermal resistance of cylindrical wall. The Fourier equation, for steady-state conduction through pipes in the normal direction to the wall surface (Fig. 13), can be written

$$
\dot{Q}=-\lambda A \frac{d t}{d r}
$$

Mathematical Modeling and Computing, Vol. 3, No.1, pp. 59-78 (2016) 
where $\dot{Q}$ is the rate of heat transfer, $\lambda$ is the thermal conductivity of the pipe, $A$ is the area normal to the direction of heat flow $(A=2 r \pi l), t$ is the temperature $\left(t_{f l}>t_{u}\right), r$ is the radius of pipe $(d=2 r)$, $l$ is the length of the pipeline.

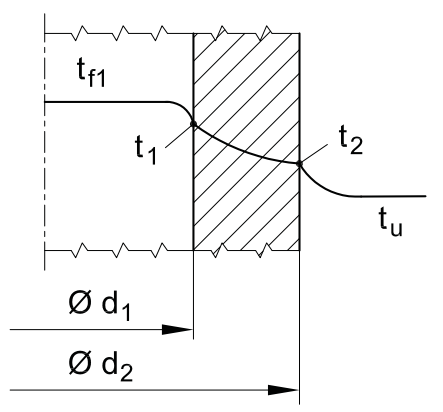

Fig. 13. One-dimensional heat conduction in a cylindrical layer.

After integration and rearranging, the rate of heat transfer takes the form:

$$
\dot{Q}=\frac{t_{1}-t_{2}}{\frac{1}{2 \pi \lambda l} \ln \frac{d_{2}}{d_{1}}},
$$

where

$$
R=\frac{1}{2 \pi \lambda l} \ln \frac{d_{2}}{d_{1}}
$$

is the conductive thermal resistance of cylindrical wall.

The insulated pipe (with both inside and outside experienced convection) is shown in Fig. 14. The thermal resistance of the pipe is given by [31]

$$
R_{p}=\frac{1}{2 \pi \lambda_{p} l} \ln \frac{d_{2}}{d_{1}}
$$

where $\lambda_{p}$ is the thermal conductivity coefficient of pipe material, $d_{1}$ and $d_{2}$ are the inner and outer diameters of the pipe. The thermal resistance of the insulation layer can be expressed as

$$
R_{i s}=\frac{1}{2 \pi \lambda_{1} l} \ln \frac{d_{2}+2 h_{1}}{d_{2}}
$$

where $\lambda_{1}$ is the thermal conductivity coefficient of the insulation layer and $h_{1}$ is the thickness of the insulation layer.

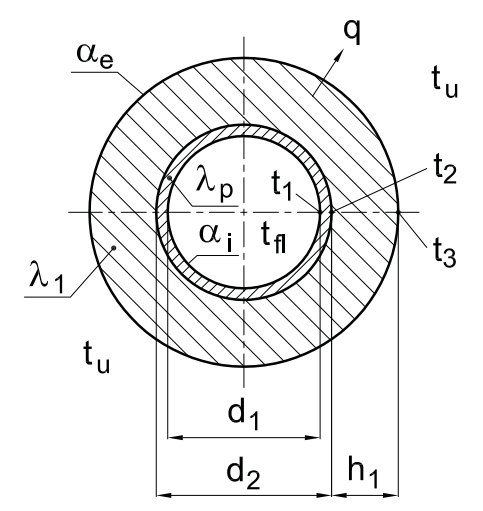

Fig. 14. Cross section of insulated pipe.

The convective thermal resistance of cylindrical wall. The equation for convective heat transfer (Newton's law of cooling) (Fig. 14) can be expressed as follows

$$
\dot{Q}=\alpha A\left(t_{f l}-t_{1}\right),
$$

where $\alpha$ is the heat transfer coefficient, $A$ is the heat transfer area of the surface, $t_{f l}$ and $t_{1}$ are the temperatures of the fluid and of the surface of internal wall, respectively.

From the equation (51) the convective thermal resistance of the surface against heat transfer for the inner surface of pipe can be expressed as

$$
R_{i w}=\frac{1}{\alpha_{i} \pi d_{1} l},
$$

where $\alpha_{i}$ is the heat transfer coefficient on the internal surface (wall) of pipe (Fig. 14.). Similarly as in the equation (52) the thermal resistance on the external surface of the insulated pipe can be expressed as follows

$$
R_{e w}=\frac{1}{\alpha_{e} \pi\left(d_{2}+2 h_{1}+\right) l},
$$

where $\alpha_{e}$ is the heat transfer coefficient on the external surface of insulated pipe (between the external surface and surround air). Using an electrical circuit analogy, the total thermal resistance equals the sum of the thermal resistances of heat transfer and conduction $\left(R_{i w}+R_{p}+R_{i s}+R_{e w}\right)$. For the insulated pipe, the rate of heat transfer is given by

$$
\dot{Q}=\frac{t_{i}-t_{u}}{R_{i w}+R_{p}+R_{i s}+R_{e w}} .
$$

Mathematical Modeling and Computing, Vol. 3, No.1, pp. 59-78 (2016) 


\subsection{Formulation of the objective function}

Calculation of the optimal thickness of an insulation layer has a quite high importance because of the valuable material cost in the investment phase as well as the heat loss in the operation phase of heat a pipe system. In general, there is widely used the one-layer insulation. The task is to determine the optimal thickness of the polyurethane foam insulation layer $\left(h_{1}\right)$ (Fig. 14). In the case of the pipe insulation, the objective (cost) function (related to one meter) includes the material costs of the pipe $\left(k_{p}\right)$ and of the insulating layer with outer jacket $\left(k_{i s}\right)$, and of the heat loss $\left(k_{h l}\right)$ as well:

$$
K=\left(k_{p}+k_{i s}+k_{h l}\right) l .
$$

The cost of the heat insulation includes the cost of the insulation layer and the material cost of outer jacket. Therefore, becomes the insulation costs are the following

$$
k_{i s}=\frac{\left.\left[\left(d_{2}+2 h_{1}\right)^{2}-d_{2}^{2}\right)\right] \pi}{4} k_{p f}+\left[\left(d_{2}+2 h_{1}\right) \pi+c_{o}\right] k_{m},
$$

where $k_{p f}$ is the specific material cost of polyurethane foam $\left(\mathrm{HUF} / \mathrm{m}^{3}\right), k_{m}$ is the specific material cost of outer cover $\left(\mathrm{HUF} / \mathrm{m}^{2}\right)$ and $c_{o}$ is the overlapping of the outer jacket $(\mathrm{m})$. The thermal resistance of outer jacket can be neglected.

The energy cost of heat loss related to one meter can be calculated as

$$
k_{h l}=\frac{\dot{Q}}{l} \tau k_{s e}=\dot{q} \tau k_{s e},
$$

where $\dot{q}$ is the rate of heat transfer related to one meter of pipeline, $\tau$ is the annual operating time of pipeline, $k_{s e}$ is the specific energy cost $(\mathrm{HUF} / \mathrm{J})$.

\subsection{Design constraints}

Constraint for admissible heat loss. It is necessary to limit the admissible heat loss from different points of view:

$$
\dot{q}=\frac{\dot{Q}}{l} \leqslant \dot{q}_{\text {allow }},
$$

where $\dot{q}_{\text {allow }}$ is the admissible heat loss.

Constraint for the temperature of the outside surface. Also, it is necessary to restrict the temperature of the outside surface of isolated pipeline $\left(t_{3}\right)$, it has to be larger than the temperature of the surrounding air $\left(t_{u}\right)$

$$
t_{u} \leqslant t_{3}
$$

The $t_{3}$ temperature can be calculated from the fact, that the same heat is transformed for all layers

$$
\frac{t_{f l}-t_{3}}{R_{i w}+R_{p}+R_{i s}}=\frac{t_{f l}-t_{u}}{R_{i w}+R_{p}+R_{i s}+R_{e w}},
$$

rearranging yields

$$
t_{3}=t_{f l}-\frac{\left(t_{f l}-t_{u}\right)\left(R_{i w}+R_{p}+R_{i s}\right)}{R_{i w}+R_{p}+R_{i s}+R_{e w}} .
$$




\subsection{The solution of the optimization problem and results}

Let us consider the following numerical example. Data: $d_{1}=0.159 \mathrm{~m} ; \quad d_{2}=0.168 \mathrm{~m}$; $c_{o}=0.01 \mathrm{~m} ; \quad k_{p f}=9100 \mathrm{HUF} / \mathrm{m}^{3} ; \quad k_{m}=900 \mathrm{HUF} / \mathrm{m}^{2} ; \quad k_{p}=700 \mathrm{HUF} / \mathrm{m} ; \quad k_{s e}=7 \cdot 10^{-7} \mathrm{HUF} / \mathrm{J} ;$ $l=10 \mathrm{~m} ; \quad q_{\text {allow }}=20, \ldots, 120 \mathrm{~W} / \mathrm{m} ; \quad t_{u}=-15^{\circ} \mathrm{C} \quad$ and $+15^{\circ} \mathrm{C} ; \quad t_{f l}=110^{\circ} \mathrm{C} ; \quad \alpha_{e}=48.8 \mathrm{~W} / \mathrm{m}^{2} \mathrm{~K} ;$ $\alpha_{i}=105.5 \mathrm{~W} / \mathrm{m}^{2} \mathrm{~K} ; \lambda_{1}=0.021 \mathrm{~W} / \mathrm{m} \mathrm{K} ; \lambda_{p}=52.3 \mathrm{~W} / \mathrm{m} \mathrm{K} ; \tau=168$ hours. The temperature dependence of the heat transfer coefficient and the thermal conductivity are neglected.

The Fig. 15. shows the optimal insulation thickness $h_{1 \text { opt }}$ depending on the heat loss and surrounding air $\left(-15^{\circ} \mathrm{C}\right.$ and $\left.+15^{\circ} \mathrm{C}\right)$.

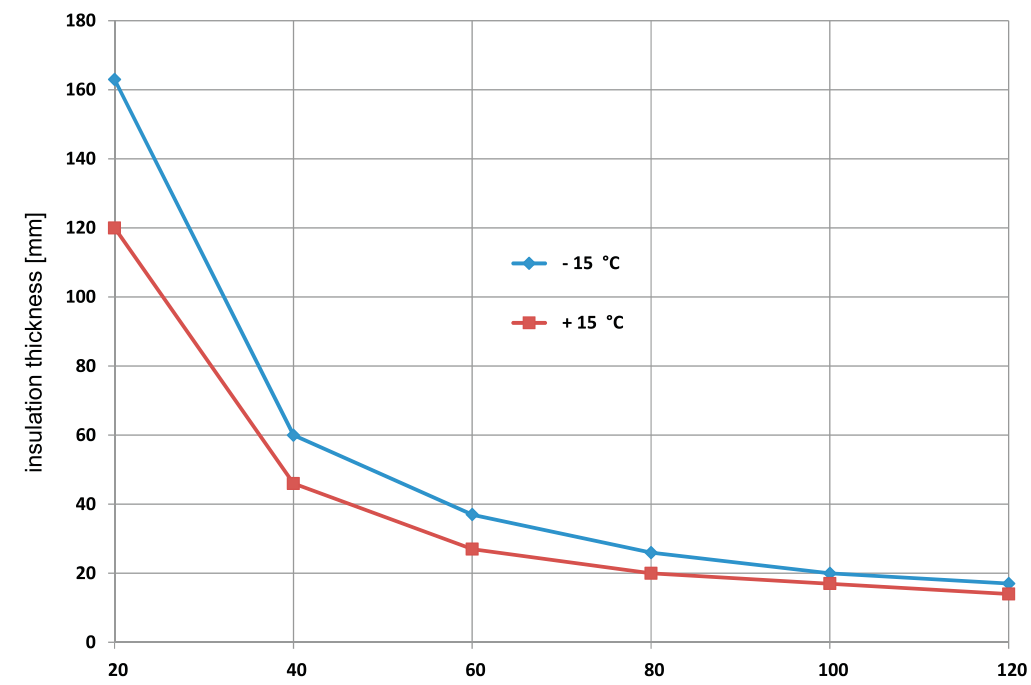

Fig. 15. Insulation thicknissible peat loss $\{\mathrm{W} / \mathrm{m}]$ vi the heat loss.

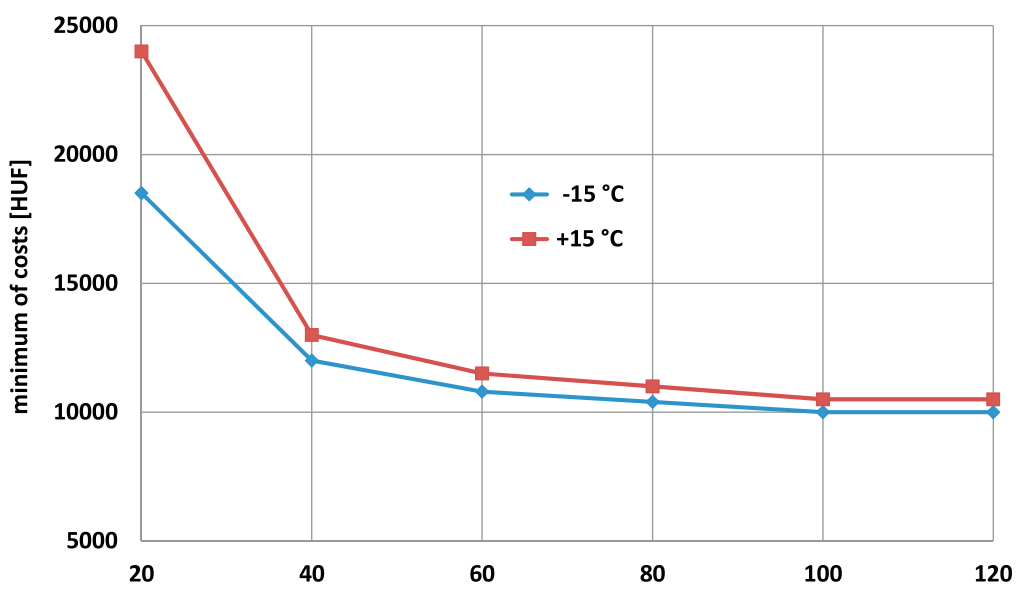

Fig. 16. Minimum $\operatorname{costs}\left(K_{\min }\right) \mathrm{VS}$. the heat loss.

The Fig. 16. shows the minimum costs $\left(K_{\min }\right)$ depending on the heat loss and surrounding air $\left(-15^{\circ} \mathrm{C}\right.$ and $\left.+15^{\circ} \mathrm{C}\right)$.

This calculation results show that it is possible to determine the optimal thickness of the insulation layer of the object with the correctly formulated objective function and under the given constraints. Thus, the reduction of the material and heat loss costs is possible. This model is also suitable for the calculation of multilayer insulation task, and also for the calculation of a spherical tank with the appropriate modification of the equations. 


\section{Conclusions}

An overview and sample cases are presented in this paper about the application of optimizing methods for engineering problems. Several approaches and methods, which are widely used in the engineering practice, are discussed. Special sample cases are presented using the modified SUMT (Sequential Unconstrained Minimization Technique) method.

The results obtained after the optimization show, that it is possible to find an economic (from engineering point of view: optimal) design to gain the maximum benefit and to cause the minimum negative impact on the natural and economic environment. Also several engineering constraints were fulfilled, such as fatigue stress limitation and local buckling criteria as well as heat loss limitation or surface temperature constraint.

[1] Xie Y. M., Steven G. P. Evolutionary structural optimization. Springer, London (1997).

[2] Farkas J. Optimum design of metal structures, Academic Publisher, Budapest (1984).

[3] Antoniou A., Lu W. S. Practical optimization. Springer, New York (2007).

[4] Schumacher A. Optimization of mechanical strctures. Springer, Berlin (2013), (In German).

[5] Dantzig G. B. Linear programming and extensions. Princeton University Press (1998).

[6] Belegundu A. D., Chandrupatla T. R. Optimization concepts and applications in engineering. Upper Sadle River. Prentice Hall (1999).

[7] Spillers W.R., MacBain K. M. Structural optimization. Springer, New York (2009).

[8] Kuhn H. W., Tucker A. Nonlinear programming. Proc. of the Second Berkeley Symposium on Mathematical Statistics and Probability. University of California Press, Berkeley, 481-490 (1951).

[9] Rao S. S. Optimization, Theory and applicatons. Wiley, New Delhi (1984).

[10] Schmit L. A. Structural design by systematic synthesis. Proc. of the Second Conference on Electronic Computation. ASCE, New York, 105-122 (1960).

[11] Caroll C. W. The created response surface techniques for optimizing nonlinear, restrained systems. Operations Research. 9, n. 2, 169-184 (1961).

[12] Fiacco A. V., McCormick G. P. Nonlinear programming: sequential unconstrained minimization techniques. Wiley, New York (1968).

[13] Wang L., Ng. A. H. C., Deb K. Multi-objective evolutionary optimization for product design and manufacturing. Springer, London (2011).

[14] Timár I. Optimierung ebener Fachwerke mit mehreren Zielfunktionen. Forschung im Ingenieurwesen. 68, n. 3, 121-125 (2004), (In German).

[15] Li W., Han Y. Multi-objective optimum design of structures. (Eds. Hernadez S., El-Sayed M., et al. Structural optimization. Computation Mechanics Publications), Southampton. 8, 35-42 (1995).

[16] Rao V. R., Savsani V. J. Mechanical design optimization using advenced optimization techniques. Springer, London (2012).

[17] Geike T., Parchem R. Genetische Algorithmen zur Optimierung von Schraubenverbindungen. Konstruktion. N. 1/2, 48-52 (2003), (In German).

[18] Pohlheim H. Evolutionäre Algorithmen - Verfahren, Operatoren, Hinweise aus der Praxis. Berlin, Heidelberg, New York: Springer-Verlag (1999), (In German).

[19] Yang X. S. Nature-inspired metaheuristic algorithm. Luniver Press (2008).

[20] Macsák G.Z., Jármai K. Solving constrained structural optimization problems with heuristic methods. GEP. N.5, 25-32 (2014), (In Hungarian).

[21] Bendsoe M. P. Optimization of structural topology, shape, and material. Springer, Berlin (1995).

[22] Kulcsár T., Timár I. Mathematical optimization in design - Overwiew and application. Acta Technica Corviniensis Buletin of Engineering. Tome V. Fascicule 2, 21-26 (2012).

[23] Affolter Chr., Weisse B. Strukturoptimierung: Topologie- und Formoptimierung für ein effizientes Produktdesign. Konstruktion. N. 7/8, 59-61 (2001), (In German).

Mathematical Modeling and Computing, Vol. 3, No. 1, pp. 59-78 (2016) 
[24] Meske R., Sauter J., Gülzer Ph. Topologieoptimierung einer Linearführung mit TOSCA und ABAQUS. Konstruktion. N. 9, 52-54 (2001), (In German).

[25] Klein M. Form optimization with higher-order finite element methods FEM of continuum structures. VDI Verlag. Düsseldorf. (2000). (In German).

[26] Timár I., Horvâth P., Borbély T. Optimierung von profilierten Sandwichbalken. Stahlbau. No. 2, 109-113. 72(2003). (In German).

[27] Timár I., Torski A., Schsukin V. About an optimum choise of parameters of the loaded three-layer plates by criterion of cost. Physiko-Mathematical Modelling and Informational Technologies. 10, 132-137 (2009), (In Ukrainian).

[28] Timár I., Horváth P. Optimal design of pipelines and spherical tank. Annals of the University of Oradea. Fascicle of Management and Technological Engineering. ISSUE \#3, 57-60 (2014).

[29] Kulcsár T., Timár I. Optimization of a welded main frame of freight bogies considering to EN 13749 standard. Deisign, Fabrication and Economy of Meteal Structures. International Conference Proceedings 2013. Miskolc, Hungary, April 24-26, 2013 (Eds. Jármai K., Farkas J.). Springer, Heidelberg (2013).

[30] Farkas J., Jármai K. Design and optimization of metal structures. Horwood Publishing, Chichester (2008).

[31] Timár I. Optimierung der Isolierstärke von Rohrleitungen. Forschung im Ingenieurwesen. 68, n. 2, 96-100 (2003), (In German).

\title{
Математична оптимізація та інженерні задачі
}

\author{
Кульксар Т., Тімар I. \\ Інженерно-механічний факультет, Університет Паннонія \\ вул.Університетсъка 10, 8200, Веспрем, Угорщина
}

Нові складні проблеми постали у всіх сегментах світової економіки за останні два десятиліття. Енергетична, екологічна, фінансова кризи, а також інтенсивне використання природних ресурсів вимагають нових методів проектування в інженерних задачах як для проектування продукції, так і для планування виробничого процесу. Ефективним засобом залишатися конкурентоспроможними є застосування оптимальних методів проектування в інженерних задачах. Розглянуто різні методи математичної оптимізації, які широко використовуються для вирішення інженерних завдань, і описуються застосування оптимізації для двох різних випадків. Перший приклад показує, як знайти оптимальні розміри зварної коробчастої рами залізничного візка, що дасть змогу мінімізувати витрати на виготовлення конструкції і задовольнятиме низку обмежень, наприклад, граничні механічні напруження, потрібний розмір, вигинання, втому металу. Інший випадок - знайти оптимальні геометричні розміри системи ізоляції труби за встановлених обмежень на втрату тепла і за обмеженої температури зовнішньої поверхні. Розв'язання цієї задачі призвело до мінімальних капіталовкладень і експлуатаційних витрат.

Ключові слова: математична оптимізачія, оптимальне проектування залізничного візка, оптимізація ізолъованого трубопроводу.

2000 MSC: $90 \mathrm{C} 90,74 \mathrm{P} 10$

UDC: 519.85 